\title{
BERNAZAR DI KUBURAN KERAMAT MUYANG BUNIN: STUDI KASUS DI DESA BUNIN KECAMATAN LOKOP SERBAJADI KABUPATEN ACEH TIMUR
}

\author{
Jahuri ${ }^{1}$, Abdullah Akhyar Nasution ${ }^{2}$ \\ ${ }^{1}$ Program Studi Sosiologi, Universitas Malikussaleh Lhokseumawe \\ Aceh-Indonesia \\ 2Program Studi Antropologi, Universitas Malikussaleh Lhokseumawe \\ Aceh-Indonesia
}

Korespondesi: Jahuri1212@gmail.com

\begin{abstract}
Abstrak: Penelitian ini bertujuan untuk mengetahui bagaiamana prosesi ziarah dan penunaian nazar yang diperaktekkan oleh masyarakat di kuburan Muyang Bunin serta untuk mengetahui motif dan alasan para peziarah melakukan ritual ziarah penunaian nazar di kuburan keramat Muyang Bunin pada masyarakat Desa Bunin Kecamatan Lokop Serbajadi Kabupaten Aceh Timur. Penelitian ini menggunakan metode kualitatif yang bersifat deskriptif. Kemudian untuk mengkaji peneliti melakukan penelusuran melalui observasi lapangan, dokumentasi dan wawancara dengan beberapa narasumber dan beberapa tokoh masyarakat seperti kadam/penjaga makam, aparat desa, peziarah dan penduduk setempat serta mengumpulkan data terkait dengan kepercayaan, tingkah laku dan ritual nazar masyarakat peziarah pada kuburan keramat Muyang Bunin. Hasil penelitian menunjukkan bahwa kegiatan nazar di kuburan keramat Muyang Bunin disebabkan beberapa hal yaitu adanya kepercayaan peziarah terhadap unsur kekeramatan pada makam tersebut, juga kepercayaan yang sudah sejak zaman nenek moyang mereka melakukan tradisi ini. Maka dari itu tidak mengherankan lagi bagi masyarakat sekitar untuk tetap melaksanakan peran yang secara turun temurun masih dilaksanakan sampai sekarang.
\end{abstract}

Kata Kunci: Keramat, Bernazar, Muyang bunin 


\section{A. Pendahuluan}

Fenomena kehidupan yang cukup menarik untuk dicermati, yaitu meningkatnya jumlah peziarah kemakam, baik makam wali maupun makammakam yang dianggap keramat. Salah satu makam yang dianggap keramat oleh masyarakat sekitar adalah makam keramat Muyang Bunin yang terletak di daerah Kecamatan Lokop Serbajadi Kabupaten Aceh Timur.

Makam bisa disebut keramat jika penghuni makam tersebut adalah orang yang memiliki pengaruh di masyarakat. Pengaruh tersebut bisa berbentuk kharisma. Sebagaimana yang diungkapkan oleh Weber bahwa kharisma adalah suatu kelebihan tertentu yang terdapat dalam karakter dan kebribadian seseorang. (Purnamasari, 2009). Kharisma akan diterapkan pada suatu mutu tertentu yang terdapat pada kepribadian seseorang, yang karenanya dia terpisah dari orang biasa dan diperlakukan sebagai orang yang dianugerahi kekuasaan atau mutu yang bersifat luar biasa, atau sekurang-kurangnya merupakan pengecualian dari hal-hal tertentu.

Kepercayaan masyarkat pada makam keramat diakui atau tidak bermula dari sebuah pemahaman teologis yang berawal dari ajaran tasawuf yang digambarkan tentang sosok yang memiliki karomah tersebut. Yang mana ada tiga hal yang menonjol pada diri mereka, yakni karamah, barakah, dan syafaat. Ketiga hal itu melekat dan menjadikannya sebagai tokoh keramat, baik ketika hidup maupun setelah meninggal, sehingga untuk mencari tiga hal itulah makamnya menjadi pusat peziarah (Purnamasari, 2009).

Ziarah ke makam leluhur maupun makam tokoh yang tersohor sangat berkaitan dengan unsur keagamaan. Makam dalam banyak kebudayaan dan kepercayaan di seluruh dunia menempati ruang spiritual yang istimewa. Makam menjadi salah satu titik sentral berlangsungnya ritual keagamaan, hampir sejajar dengan rumah ibadah satu agama: masjid, candi, dan lain-lain. Sebagai tempat diabadikannya jasad orang yang sudah meninggal, makam dipercaya sebagai tempat bersemayamnya ruh orang yang meninggal. Berziarah ke makam merupakan cara untuk berhubungan kembali secara spiritual dengan arwah yang dimaksud (Romdhoni, 2015). 
Menurut Kadam/Tgk Aliamat Muyang Bunin merupakan seorang pahlawan yang berjuang menyebarkan Agama Islam pada zaman dahulu. Namun dia terpisah dengan teman-temannya dan bertempat tinggal di Bunin ini yang dirintis dari awal sehingga sampai sekarang Desa Bunin ini dapat di duduki oleh anak cucunya. Jika dilihat secara kasat mata kuburan keramat Muyang Bunin Nampak sama dengan makam-makam lainnya yang ada disana, yang membedakan hanya saja kalau makam lainnya diluar rumah sedangkan kuburan keramat Muyang Bunin ini berada dalam rumah yang dibuat oleh masyarakat daerah sekitaran. Namun, kharisma yang dimiliki oleh Muyang Bunin bagi penduduk nampak berbeda karena perjuangan dan jasa-jasa yang telah diberikannya membuat orang disekitarnya, atau yang mengenalnya dari sejarah, menganggap bahwa beliau adalah orang suci yang dekat dengan Allah SWT. Dan bisa memberikan karomah bagi siapa saja yang mendoakannya.

Kuburan Muyang Bunin salah satu kuburan yang dianggap Keramat, juga dipercayai oleh masyarakat sekitar Aceh Timur khususnya masyarakat Kecamatan Lokop Serbajadi. Bahkan bukan hanya masyarakat Kecamatan Lokop Serbajadi saja yang berkunjung untuk bernazar di tempat tersebut tetapi juga dari daerah luar kabupaten juga ada, seperti dari Aceh Tengah, Gayo lues dan juga Aceh Tenggara mereka percaya bahwa ada suatu nilai tertentu yang terdapat di kuburan keramat Muyang Bunin tersebut, sehingga banyak masyarakat yang mempercayai kuburan keramat Muyang Bunin sebagai tempat untuk bernazar dan meminta perlindungan dari mara bahaya yang datang tak terduga dan juga lainlainnya.

Fenomena yang pernah terjadi yaitu ketika seseorang yang pernah bernazar ditempat tersebut telah mendapatkan keinginannya maka mereka akan menyembelih kambing atau melakukan sesuatu pada kuburan keramat Muyang bunin, sebagaimana kejadian tersebut sudah bukan hal yang asing lagi bagi masyarakat. Karena setiap bulan pada umumnya, masyarakat datang menziarahi kuburan keramat Muyang Bunin dengan tujuan untuk bernazar.

Dalam hal yang dinazarkan misalnya kambing, orang yang bernazar membawakan bahan-bahan mentah dari rumah untuk di masak seperti beras 
beserta bumbu-bumbu lainnya. Sedangkan peralatan untuk memasak sudah tersedia di tempat kanduri tersebut (Muyang). Selain memasak ditempat bernazar ada juga yang namanya bernazar Selengkap atau biasa di sebut oleh masyaraka dengan sebutan niat Selengkap yang masaknya tidak perlu ditempat karena cara membuatnya tidak begitu berat seperti memasak masakan kambing. adapun isi dalam nazar Selengkap tersebut adalah nasi beserta kuah ayam, pulut kuning, apam/serabi, bertih, alat peseujuk beserta alat-alat makan untuk kanduri lainnya.

\section{B. Metode Penelitian}

Pendekatan penelitian yang digunakan adalah Kualitatif Deskriptif, yaitu pembahasan penelitian ini disajikan dan dianalisis dalam bentuk uraian kata-kata lisan, tertulis, dan tingkah laku yang dapat diamati dari orang-orang yang diteliti. Subjek dalam penelitian ini ditentukan dengan metoda Purposive, yaitu dimana pengambilan atau penarikan sampling dilakukan dengan memilih subjek (informan) berdasarkan kriteria spesifik yang telah ditetapkan oleh peneliti. Dalam hal ini, yang dijadikan subjek pada penelitian ini adalah tokoh-tokoh masyarakat yang mengetahui seluk-beluk tentang Bernazar di Kuburan Keramat Muyang Bunin, yang mana diantaranya yaitu: Tengku/Kadam Muyang Bunin yang berperan sebagai penjaga Kuburan Keramat tersebut sekaligus menjadi orang yang membacakan do'a kanduri saat nazar dilaksanakan, Masyarakat yang sudah pernah melepaskan nazarnya di kuburan keramat tersebut, dan masyarakat setempat. Teknik yang digunakan untuk memperoleh data dengan observasi dan wawancara dan studi dokumentasi.

\section{Pembahasan}

\section{1) Gambaran Umum Desa Bunin}

Sejarah pembangunan Desa Bunin diawali oleh keinginan sekelompok orang yang dipimpin oleh Muyang Bunin sendiri untuk membangun sebuah pemukiman ratusan tahun yang lalu yang awalnya dinamai dengan tembuni yang artinya tempat persembunyian, dan dengan seiring berkembangnya generasi terbaru maka dirubahlah menjadi Bunin. Desa Bunin merupakan salah satu Desa yang terletak di Kemukiman Bunin Kecamatan Lokop Serbajadi Kabupaten Aceh 
Timur yang berjarak $6 \mathrm{~km}$ dari pusat Kecamatan, luas wilayah Desa Bunin adalah 4 Ha, yang terbagi kedalam 2 (dua) dusun yaitu Dusun Bunin Lama dan Dusun Bunin Baru dengan jumlah penduduk 319 jiwa pada saat itu, yang mayoritas penduduknya bermata pencaharian sebagai petani kebun dan petani sawah.

\section{Aspek Agama}

Agama dan kepercayaan merupakan suatu yang asas dalam kehidupan manusia. Agama adalah seperangkat aturan atau undang-undang yang mengikat manusia sebagai pedoman hidupnya. Karena dengan beragama kehidupan kita akan menjadi teratur dan selaras sesuai dengan ajaran-ajaran agama. Sedangkan kepercayaan merupakan salah satu ciri dari agama, melalui agama dan kepercayaan inilah manusia melakukan hubungan dengan tuhan yang di pandang mempunyai pengaruh dalam kehidupan manusia. agama yang dianut oleh masyarakat Desa Bunin hanya terdiri dari satu agama yaitu agama Islam. Mengenai jumlah penduduk Bunin berdasarkan agama menunjukkan bahwa mayoritas penduduk Desa Bunin menganut agama Islam dengan persentase 100\%. Masyarakatnya beragama Islam namun pada kesehariannya masih banyak masyarakat yang menganut kepercayaan animisme dan dinamisme.

\section{Sosial Budaya Masyarakat Desa}

Masyarakat pada umumnya tidak lepas dari keadaan sosial yang terjadi dalam kehidupan, sebab masyarakat adalah gambaran yang membentuk obyekobyek yang memberinya arti, mengambil kesesuaiannya dengan tindakan, dan mengambil keputusan berdasarkan penilaian tentang kehidupan sosial yang ada dalam kehidupan masyarakat. Salah satu sosial budaya yang terdapat di Desa Bunin tolong menolong pada saat acara kanduri.

Masyarakat Desa Bunin melakukan tolong menolong pada saat acara kanduri, baik itu kanduri pernikahan maupun kanduri acara-acara lainnya, mereka semua saling bantu membantu misalnya: orang yang menunaikan nazarnya di Muyang Bunin, orang yang melepaskan nazarnya ini mengundang orang sekitaran Desa Bunin dengan tujuan agar ada yang membantunya untuk memasak dan lainnya, dan orang yang diundangpun tidak datang dengan tangan kosong biasanya mereka datang dengan membawakan beras, kelapa dan lainnya yang bisa 
digunakan saat acara kanduri tersebut terlaksanakan. Budaya ini dilakukan secara turun temurun mulai dari nenek moyang dahulu dan sampai sekarang masih terlaksanakan.

Berikut wawancara dengan Ibu Aminah:

"Pada saat ada acara kanduri baik itu kanduri pernikahan dan kandurikanduri lainnya kami disini saling membantu orang yang sedang mengadakan acara, dan kami juga tidak berperan sebagai tamu undangan tetapi kami juga berperan sebagai pekerja dalam acara yang dilaksanakan tersebut, kami saling tolong menolong untuk menyiapkan bahan-bahan dan peralatan-peralatan yang dibutuhkan juga kami membawakan beras,gula garam, serta bahan-bahan lainnya yang bisa dipergunakan dalam acara tersebut. Dan budaya ini sudah ada mulai dari nenek moyang kami dahulu dan Alhamdulillah masih terlaksankan sampai saat sekarang ini. (wawancara 23 juli 2018)

Dari wawancara diatas dapat disimpulkan bahwa kehidupan sosial masyarakat Desa Bunin ini masih sangat erat menjalin kebersamaan dan kelompok dalam suatu kegiatan, budaya ini timbul dari nenek moyang mereka dan masih berjalan sampai sekarang ini.

Sejarah Muyang Bunin

Belum ada yang menulis dan menemukan karya ilmiah atau buku induk yang menerangkan riwayat Muyang Bunin. Cerita perjalanan hidup Muyang Bunin akhirnya diperoleh dari keterangan para sesepuh dan masyarakat yang mengetahui sejarah Muyang Bunin, oleh karena itu, dalam menulis riwayat hidup Muyang Bunin ini banyak didominasi oleh cerita-cerita tutur sebagai pelengkap cerita perjalanan Muyang Bunin. Muyang Bunin merupakan salah satu kawan dari Muyang Tualang, pada waktu itu sebagai salah satu ulama besar membawa syiar agama islam, sewaktu beliau pertama membuka desa Bunin.

Nama asli dari Muyang Bunin sendiri adalah Syeh Tgk Ibrahim tapi yang sering dipanggil dengan sebutan Muyang Bunin. Arti dari Muyang sendiri adalah nenek moyang sedangkan Bunin ialah persembuniyan. Dikenal dengan nama sebutan Muyang Bunin karena beliaulah pertama sekali yang membangun dan merintis sebuah perkampungan yang dinamai Bunin tersebut, dan Bunin sendiri dalam artian tembuni yaitu persembuyian, yang dimaksud dari persembuyian sendiri ialah dengan maksud pertama sekali dibangun beliau mengatakan bahwa 
hasil dari perintisannya setidaknya layak sebagai tempat persembuyian, dari situlah mulai dinamai dengan Bunin dan sekarang dikenal dengan Desa Bunin. Sehingga dengan terus berjalannya waktu dan keturunan-keturunannya menyebut beliau dengan sebutan Muyang Bunin.

Muyang Bunin merupakan salah satu ulama penyebar agama islam yang memiliki karomah atau kelebihan yang tidak dimiliki manusia pada umumnya. Sehingga sekarang dikenal dengan adanya kekeramatannya masyarakat berkunjung ke kuburannya dengan tujuan berdo'a dan bernazar agar do'a dan nazarnya diterima oleh Allah SWT.

\section{2) Prosesi Bernazar di Kuburan Keramat Muyang Bunin}

\section{Terlebih Dahulu Menemui Kadam Muyang}

Bernazar di kuburan Muyang Bunin ini rupanya sudah menjadi budaya bagi masyarakat Kecamatan Lokop Serbajadi, dan orang yang melaksanakan nazarnya harus mengikuti aturan yang sudah diterapkan sejak zaman adanya kuburan keramat Muyang ini, diantaranya ialah:

1. Setiap pengunjung yang akan menunaikan nazar terlebih dahulu memberitahukan kepada kadam/Tgk penjaga kuburan sekaligus yang membacakan do'a pada pelaksanaan nazar.

2. Para peziarah dilarang berhura-hura/ria di sekitaran kuburan.

3. Para pengunjung atau peziarah tidak boleh melakukan perbuatan yang dilarang dalam syariat Islam, seperti duduk-duduk dan menciumi batu nisan.

4. Biasanya para pengunjung yang meminta bantuan kepada kadam saat melakukan ritual ziarahnya ke kuburan tersebut, karena tidak sembarang orang yang bisa masuk begitu saja kedalam rumah kuburan.

5. Apabila peziarah dalam kunjungan dengan niat yang tidak baik, maka kadam Muyang Bunin tidak bertanggung jawab apabila terjadi sesuatu yang tidak diinginkan. Maka dari itu sangat dianjurkan para pengunjung yang mau menunaikan nazarnya sangat terlebih dahulu harus memberitahukan kepada kadam/penjaga kuburan. 
Berikut keterangan dari beberapa orang yang pernah menunaikan nazarnya di Muyang Bunin:

"Saya pernah melepaskan nazar saya ke Muyang Bunin ini, namun saya terlebih dahulu menemui Tgk/kadam Muyang, karena tidak sembarangan orang yang akan melepaskan nazarnya itu pergi begitu saja ke kuburan atau tempat kanduri yang sudah disediakan, juga orang yang datang kekuburan tersebut dilarang juga berhura-hura karena takut sesuatu yang tidak diinginkan akan terjadi, apabila sesuatu terjadi pada salah satu dari pelepas ziarah Tgk/kadam Muyang Bunin tersebut tidak bertanggung jawab, ini sudah diperingatkan sejak zaman dahulu, dan alhamdulillah sampai sekarang masih terlaksanakan seperti peraturan-peraturan yang sudah di tetapkan zaman dulu". (wawancara 9 juni 2018)

Dari wawancara di atas dapat dipahami bahwa peziarah yang menunaikan nazarnya tidak bisa secara langsung menunaikan nazarnya kekuburan keramat Muyang Bunin tersebut, akan tetapi terlebih dahulu menemui Kadam/Tgk yang menjaga sekaligus orang yang membacakan doa disaat kanduri dilaksanakan, juga peziarah yang datang menunaikan nazarnya sangat dilarang berhura-hura di sekitaran kuburan keramat Muyang Bunin. Karena apabila terjadi sesuatu diluar keinginan Kadam/Tgk penjaga kuburan keramat tersebut tidak bertanggung jawab.

Tata cara pelaksanaan ziarah kubur yang dilakukan para peziarah di kuburan keramat Muyang Bunin di Kecamatan Lokop Serbajadi Kabupaten Aceh timur antara lain:

1. Para pengunjung yang menunaikan nazarnya membawa sesuai yang seperti di nazarkannya, misalnya menazarkan akan menyembelih seekor kambing maka harus membawa beras, kambing beserta bumbu-bumbu lainnya yang akan dipergunakan nantinya untuk dimasak di tempat kanduri.

2. Bagi yang mau menunaikan nazarnya diharuskan terlebih dahulu untuk menemui kadam/penjaga kuburan tersebut untuk meminta izin bahwa sanya mau melepaskan nazarnya dan sekaligus di damping atau dipimpin oleh kadam sendiri.

3. Setelah selesai masak-memasak para yang melepaskan nazarnya pergi bersama kadam/penjaga (kubur) dari tempat kanduri ke makam Muyang 
Bunin. Guna untuk menyampaikan kepada ahli kubur melalui do'a bahwa nazarnya sudah terlepaskan.

4. Dalam tata cara pelaksanaan nazarnya setiap pengunjung ke kuburannya disarankan untuk mensucikan diri dulu dengan berwudhu dahulu sebelum memasuki area makam Muyang Bunin.

5. Kemudian memasuki makam dengan mendahulukan kaki kanan, dan keluar dengan menggunakan kaki kiri.

6. Mengucapkan salam ketika memasuki area makam seperti yang di syariatkan oleh ajaran Islam.

7. Kemudian duduk di area makam dan kadam/penjaga (kubur) akan bertanya apa tujuannya? Dan hajadnya apa? Kemudian kadam/penjaga (kubur) menjelaskan bahwa melepas nazar ke kuburan Muyang Bunin ini dilarang jika bertujuan meminta dengan makam atau ahli kubur. Dan kadam menjelaskan "kita berdo’a disini meminta kepada Allah. Berharap Allah mengabulkan lantaran kita berdo'a di dekat orang yang dekat dengan Allah.

8. Kemudian kadam/ penjaga (kubur) mempersilahkan peziarah untuk memanjatkan do,a atau menyampaikan hajadnya baik lisan maupun dalam hati.

9. Setelah itu kadam/ penjaga (kubur) memimpin doa.

10. Kemudian setelah itu kadam/penjaga (kubur) memberi waktu kepada para peziarah yang mau mengirim do'a untuk ahli kubur.

11. Setelah itu para peziarah yang melepaskan nazarnya kembali ketempat kanduri bersama kadam/penjaga (kubur) dan baru kanduri bisa dimula

12. Dalam pelaksanaan kanduri Kadam/penjaga (kubur) membacakan ayatayat suci Al-Qur'an, hal ini dilakukan dengan tujuan mengirim do'a untuk ahli kubur agar segala perbuatannya di sisi Allah dan dilapangkan kuburnya. 
Tabel 4.4

Bagan Prosesi Bernazar

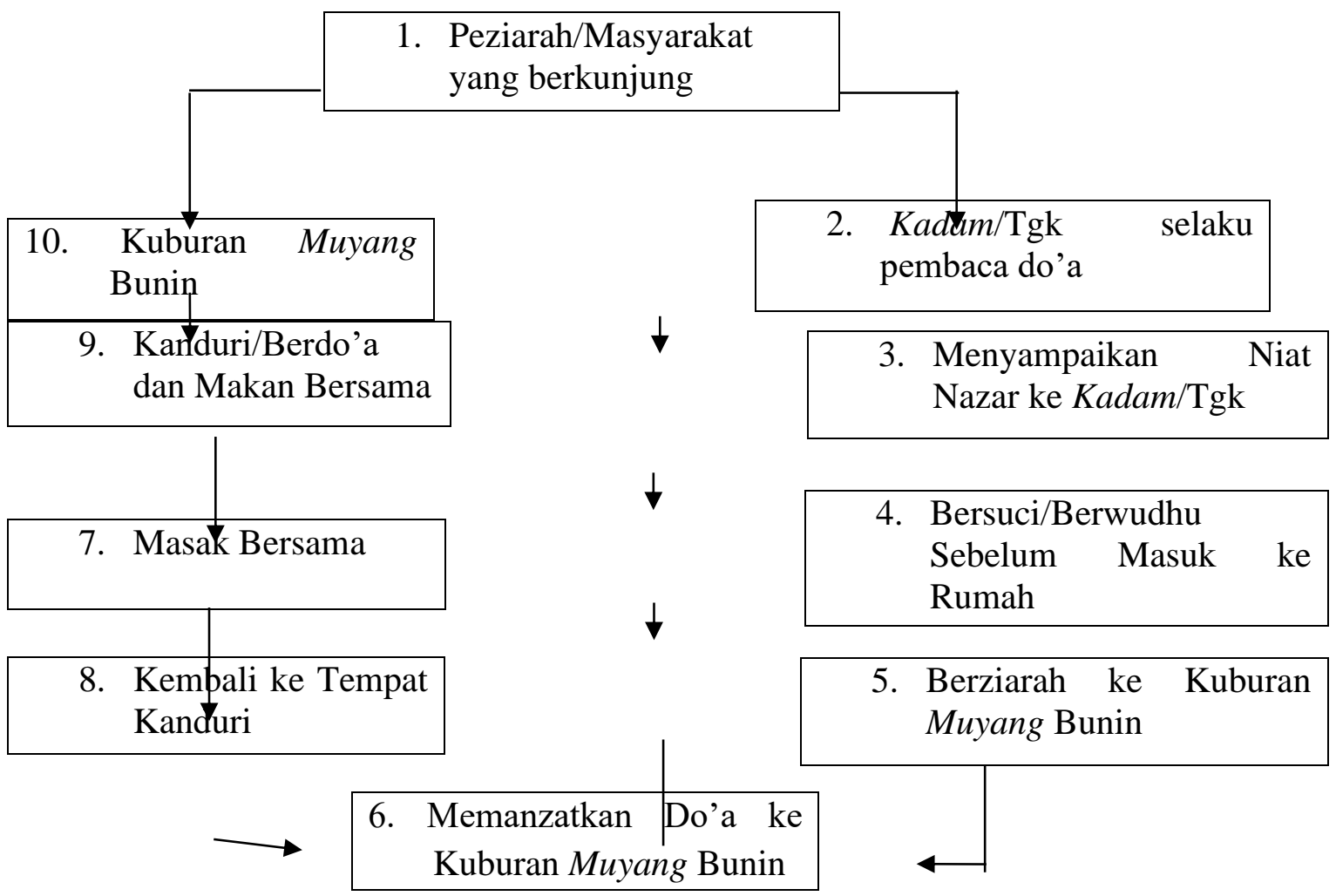

Dari bagan di atas menujukkan bahwa kuburan keramat Muyang Bunin saling berhubungan, antara peziarah dan Kadam/Tgk yang berperan sebagai pembaca do'a saat nazar yang akan dilaksanakan di tempat yang sudah di sediakan sebagai tempat kanduri atau berdo'a dan makan bersama.

\section{Masak Bersama}

Dalam proses memasak biasanya orang yang akan menunaikan nazarnya tersebut beberapa hari sebelum akan menunaikan nazarnya tersebut, mereka mengundang masyarakat yang bertempat tinggal di sekitaran desa tersebut dan juga mengundang saudara-saudara terdekat juga dengan tujuan agar dalam proses memasak nantinya biar bisa masak bersama atau bisa dikatakan dengan saling bantu membantu.

Disini masyarakat menggunakan kayu bakar, bukan karena mereka tidak kenal dengan yang namanya kompor gas, akan tetapi bagi masyarakat sekitaran memasak dengan menggunakan kayu bakar adalah bagian upaya merawat tradisi yang sudah ada dari zaman pertama kali kuburan Muyang Bunin ini di anggap 
keramat. Biasanya para pelepas nazar sebelum menunaikan nazar dalam acara masak-memasak ini terlebih dahulu sudah menyiapkannya dan membawakannya ke tempat masak.

\section{3) Motif Melakukan Ziarah ke Kuburan Muyang Bunin}

Manusia dalam melakukan sesuatu biasanya muncul dari adanya dorongan atau rangsangan yang menimbulkan seseorang rela atau bersedia menghabiskan beberapa lama waktunya untuk melakukan sesuatu itu, sama halnya dengan kegiatan nazar. Seseorang yang melakukan aktifitas nazar di kuburan tidak terlepas dari adanya dorongan atau rangsangan dan motif.

1. Motif Agama

2. Motif Keselamatan

3. Motif Mencari Berkah

4. Motif karena Nazarnya Terkabulkan

Hubungan Bernazar dengan Teori Interaksionisme Simbolik

Interaksi manusia selalu dipenuhi dengan simbol-simbol. Baik dalam kehidupan sosial maupun kehidupan diri sendiri. Sehingga diri tidak terisolasi, melainkan bersifat sosial. Dimana manusia dipandang dan diperlakukan sebagai diri sendiri sekaligus sifat sosial, hal ini sesuai seperti yang dikemukakan oleh teori interaksi simbolik. Dalam penelitian ini peneliti memfokuskan pada masalah bernazar di kuburan keramat Muyang Buni. Interaksi simbolik mengandung inti dasar pemikiran umum tentang komunikasi dan masyarakat. Ada satu varian interaksi simbolik yang dapat membantu menggambarkan dari fenomena di atas yaitu teori Hebert Blumer.

Blumer berpendapat bahwa, sebelum memberikan makna atas sesuatu terlebih dahulu seseorang akan melakukan serangkaian kegiatan berupa: memilih, memeriksa, mengelompokkan, memprediksi dan membandingkan setiap makna dalam kaitannya dengan situasi, posisi, dan arah tindakannya. Dalam interaksionisme simbolis, seseorang memberikan informasi hasil dari pemaknaan simbol dari prespektifnya kepada orang lain sehingga orang-orang menerima informasi tersebut akan memiliki prespektif lain dalam memaknai informasi yang disampaikan aktor pertama. 


\section{Kesimpulan}

Dari hasil penelitian dan pembahasan yang telah dipaparkan pada bab sebelumnya dapat diambil beberapa kesimpulan mengenai Bernazar di Kuburan Keramat Muyang Bunin di Desa Bunin Kecamatan Lokop Serbajadi Kabupaten Aceh Timur.

1. Menurut masyarakat Kecamatan Lokop Serbajadi Kabupaten Aceh Timur, kuburan Muyang Bunin adalah salah satu kuburan tokoh ulama yang menyebarkan agama pada zaman dahulu yang memiliki kharisma atau aulia, sehingga masyarakat menjadikan Muyang Bunin sebagai tempat meminta permohonan karena dianggap beliau dekat dengan Allah maka melalui beliaulah masyarakat menyampaikan nazarnya kepada Allah.

2. Pengaruh ziarah kubur Muyang Bunin terhadap agama islam masyarakat Kecamatan Lokop Serbajadi memberikan pengaruh positif dan negative. Berpengaruh positif bagi peziarah yang mengetahui tata cara yang sesuai dengan syara', maka pelaksanaannya tidak bertentangan dengan agama islam, dengan berdo'a kepada Allah mendo'akan ahli kubur dan berdo'a untuk diri sendiri hanya memohon kepada Allah bukan meminta kepada kuburan Muyang Bunin itu merupakan suatu ibadah. Bernazar atau berziarah ke kuburan juga bisa mengingatkan manusia pada kematian hal ini dapat mengingatkan manusia pada kematian maka hal ini dapat meningkatkan keimanan seseorang kepada sang pencipta.

\section{Saran}

Berdasarkan hasil penelitian dari uraian-uraian atau pembahasan dan kesimpulan yang sudah dijelaskan dari hasil penelitian maka ada beberapa saran dari penulis di antaranya sebagai berikut:

1. Bagi masyarakat dan peziarah hendaklah dapat memelihara dan melestarikan tradisi nazar dengan baik. Hal ini dikarenakan agar tidak adanya kesalah pahaman, antara nazar dan syirik. Karena masih banyak masyarakat awam yang menggunakan kuburan sebagai tempat pertolongan duniawi, bukan semata-mata kepada Allah. 
Aceh Anthropological Journal, Vol. 4, No. 1 , hlm: 75-89, April 2020

2. Kepada para peziarah yang datang hendakya dalam pelaksanaan nazar harus sesuai dengan tata cara yang telah ditentukan oleh ajaran Islam. 


\section{DAFTAR PUSTAKA}

Abdau, Luzman. (2014). Ritual Pesugihan di Gunung Kemungkus (Studi Diskriptif tentang Ritual di Gunung Kemungkus). Universitas Airlangga.

Ahmadi, Dani. (2008). Interaksi Simbolik: Suatu Pengantar. MEDIATOR, Vol 9, No.2.

Husaini Usman, dan Purnomo Setiady Akbar. (2009). Metodelogi Penelitian Sosial. Jakarta: Bumi Aksara.

Irmasari, Mirta. (2012). Makna Ritual Ziarah Kubur Angku Keramat Junjung Sirih Oleh Masyarakat Nagari Paninggahan. Sosiologi FIS UNP.

Jamaluddin. (2014). Tradisi Ziarah Kubur dalam Masyarakat Melayu Kuatan. UIN Sultan Syarif Kasim Riau, Vol 11, No.2.

Koentjaraningrat. Sejarah Teori Antropologi I. Toko Buku Karsa Murni.

Laksmi. (2017). Teori Interaksionisme Simbolik dalam Kajian Ilmu Perpustakaan dan Informasi. Volume 1, Number 1.

Mauss, Marcel. (1992). Pemberian: Bentukdan Fungsi Pertukaran di Masyarakat Kuno. Jakarta: Yayasan Obor Indonesia.

Moleong, Lexy. (2010). Metode Penelitian Kualitatif. Remaja Rosda Karya:Bandung.

Mujib, M.Misbahul. (2016). Tradisi Ziarah Dalam Masyarakat Jawa: Kontestasi Kesalehan, Identitas Keagamaan Dan Komersial. UIN Sunan Kalijaga Yogyakarta, Jl. Marsda Adisucipto Yogyakarta, 55281, Vol 14, No.2.

Nasruddin. (2013). Teori Munculnya Religi (Tinjauan Antropologis Terhadap Unsur Kepercayaan dalam Masyarakat).

Noresah, Baharom. (2005). Kamusdewan. C.4 Selangor: DawamaSdnBhd, h.1079.

Purnamasari, Nia. (2009). Makam Keramat dan Perubahan Sosial (Studi Kasus Di Masyarakat Sekitar Makam Dalem Cikundul, Majalaya, Cianjur). Fakultas Ushuluddin Dan Filsafat

Ranchman, Maman. (2000). Strategi dan Langkah-Langkah Penelitian. Semarang:IKIP Semarang Press.

Romdhoni, Ali. (2015). Relasi Makam Pesantren Dan Pedagang: Pengaruh Ziarah Terhadap Pendidikan dan Ekonomi Di Kajen Kabupaten Pati. Jurnal SMaRT Volume 01 Nomor 02.

Shyadan. (2017). Ziarah Prespektif Kajian Budaya (StudiP ada Situs Makam Priuk Jakarta Utara). Jurnal Studi Agama dan Masyarakat, Volume 13, Nomor 1. 
Subri.(2015). Ziarah Makam Antara Tradisi dan Praktek Kemusyrikan. Jurnal sosiologi.Stain Sas Ba bel.

Sugiyono, Memahami Penelitian Kualitatif, Bandung. Alfabeta, 201.

Suriani, (2017). Tradisi Ziarah Pada Makam Dato Tiro Kecamatan Bontotiro Kabupaten Bulukumba. Fakultas Adab Dan Humaniora Uin Alauddin Makassar.

Zakariyya, Abi. (2001). Al-Majmuk, Syarah al-Muhazzablil Shirazi, j.7.DarIhya Turathal-Arabi. 